\title{
LONGEVITY AND LIFE EXPECTANCY
}

Cesare Marchetti

International Institute for Applied Systems Analysis

Laxenburg, Austria

RR-97-11

September 1997

Reprinted from Technological Forecasting and Social Change, Volume 55, Number 3, July 1997.

International Institute for Applied Systems Analysis, Laxenburg, Austria Tel: +43 2236807 Fax: +43 223673148 E-mail: publications@iiasa.ac.at 
Research Reports, which record research conducted at IIASA, are independently reviewed before publication. Views or opinions expressed herein do not necessarily represent those of the Institute, its National Member Organizations, or other organizations supporting the work.

Reprinted with permission from Technological Forecasting and Social Change, Volume 55, Number 3, July 1997.

Copyright (C) 1997, Elsevier Science Inc.

All rights reserved. No part of this publication may be reproduced or transmitted in any form or by any means, electronic or mechanical, including photocopy, recording, or any information storage or retrieval system, without permission in writing from the copyright holder. 


\title{
Longevity and Life Expectancy
}

\author{
CESARE MARCHETTI
}

\begin{abstract}
The increase in life expectancy at all ages during the last two centuries is in need of a quantitative model capable of resuming the whole process under a single concept and simple mathematics. The basic hypothesis was that through improved hygiene, medicine, and life-style, the stumbling blocks to the full expression of longevity were progressively removed. The mathematics of learning processes was then applied to the secular evolution of life expectancy at various ages. The hypothesis proved very fertile. Logistic equations fit long strings of statistical data, covering the evolution of life expectancy at various ages, for both sexes, and in many European nations for almost two centuries. These life expectancy increases seem to move progressively to a common asymptote of about 79 years for men and about 84 years for women. It is suggested that these values are taken as a definition of longevity, presumably explicitating a coding in DNA. The evolution of life expectancy during the last couple of centuries appears to follow consistent paths precisely mapped with simple mathematics. This opens the way to more integrated and holistic theories. . (c) 1997 Elsevier Science Inc.
\end{abstract}

\section{Introduction}

The evolution of hygiene, nutrition, and medicine during the past two centuries has brought spectacular results in reducing infant mortality, in controlling infectious diseases and other ailments, and in increasing life expectancy, not only at birth, but in different measures at all ages.

In this article the evolution of life expectancy is examined historically for various European nations, at various ages, and according to sex. Appropriate logistic equations describe the facts and extrapolate into the future giving the doctor an indication of what is still to be accomplished and the demographer the tools with which to evaluate the aging of European populations in the next 20 years.

\section{Methods}

This analytical technique has been applied in many areas of sociology and economy, but as far as I know, not yet to the subject of life expectancy. In a nutshell, I posit that the increase in life expectancy is the product of a learning process to remove the accidents and obstacles on the way to the full life potential of an individual: longevity.

Learning processes follow precise mathematical guidelines, and one of them, the learning of language by a child, is reported in Figure 1 . This figure is important because

CESARE MARCHETTI is Institute Scholar at the International Institute for Applied Systems Analysis, Laxenburg, Austria.

Address correspondence to Cesare Marchetti, International Institute for Applied Systems Analysis, A-2361 Laxenburg, Austria. 


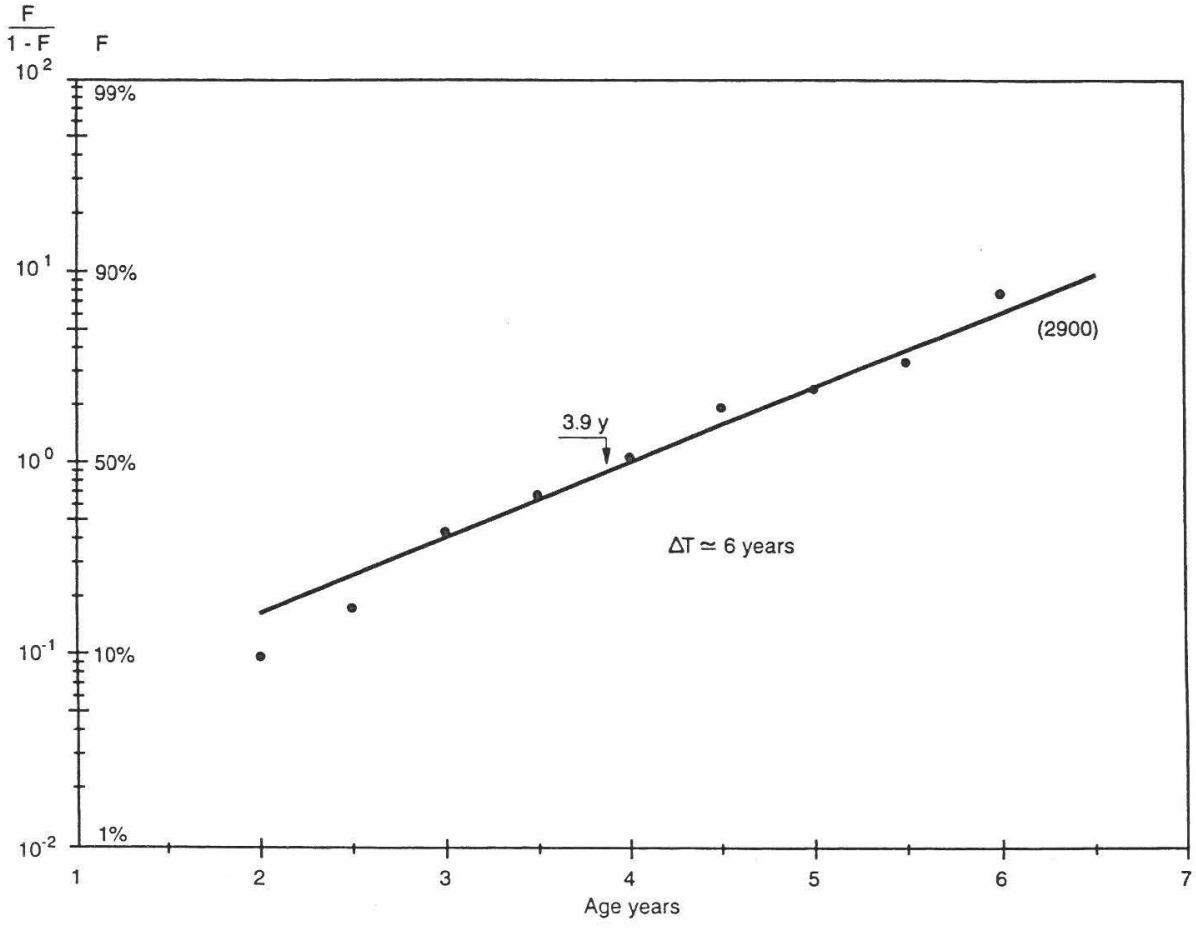

Fig. 1.

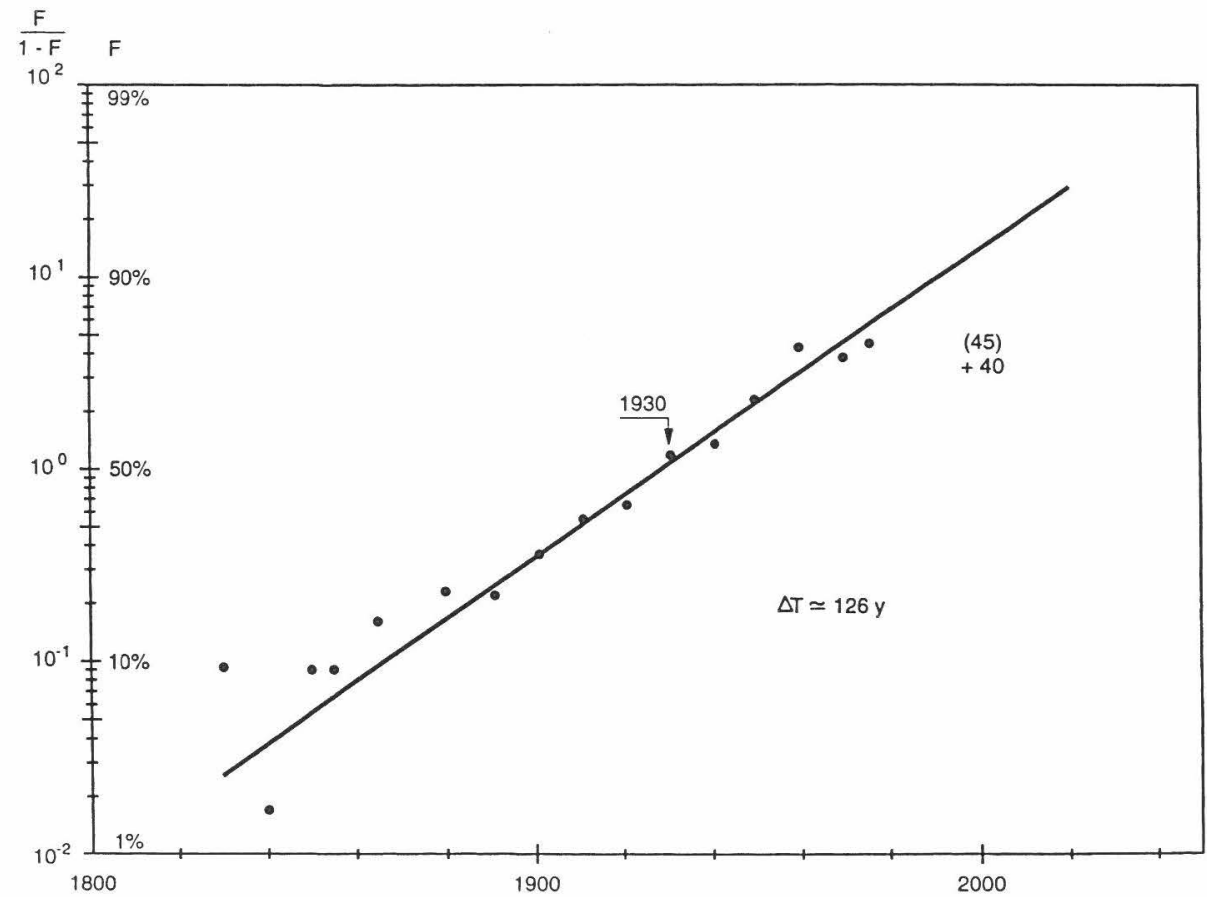

Fig. 2. 


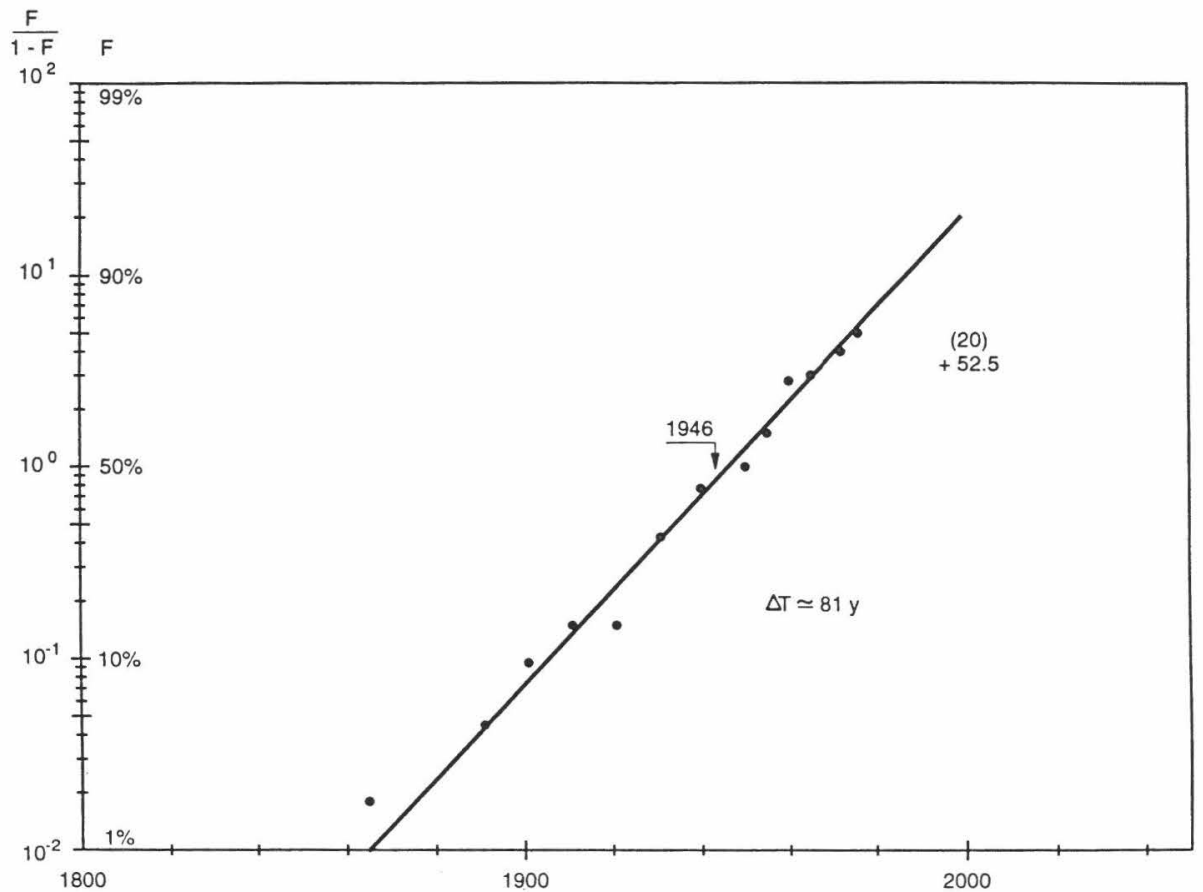

Fig. 3. Evolution of life expectancy at age 10 for Norwegian females. Life expectancy at age 10 for Norwegian females was already $52.5+10=62.5$ years in the mid-1800s. The increase will be about 20 years at saturation (at the moment it is about 18 years). The time constant is relatively short, 81 years, and the maximum speed of the growth in life expectancy was fairly recent, in 1946. Source: [7].

it condenses the principles of the methodology and of the formalism used in the article. The number in parenthesis represents the asymptote, the saturation level, which for the child gives about 2400 words in his vocabulary. The evolution of the vocabulary with age can be monitored by the number of words under control, expressed as the fraction $(\mathrm{F})$ of the final vocabulary. Then $1-\mathrm{F}$ represents the fraction still to conquer. The figure represents the $\log$ of the ratio F/1-F. The reason for choosing this representation

Fig. 1. Vocabulary of a growing child: The paradigmatic case of a learning process. Learning to speak can be monitored by measuring the vocabulary that a child has under control. The final size of this vocabulary is about 3000 words for a boy. The figure shows the fraction $(F)$ of this vocabulary under control at various ages. The halfway point (about 1500 words) is at 3.9 years. The value of $\Delta \mathrm{T}=$ 6 years gives an idea of the speed of the process. It is the time elapsed between $F=0.1$ and $F=0.9$, covering a major part of the learning process. The fitting line is a growth curve, the $\mathrm{S}$ logistic, drawn as a straight line by using the Fisher-Pry transform. Source: [6].

Fig. 2. Evolution of life expectancy at birth for Norwegian females. The data for this analysis come from Flora [7] and all the time series have been used in their full extension. A "wave" of life expectancy increase appears to start around 1800 adding, at saturation, about 45 years to the 40 years of life expectancy in 1800 . F represent the fraction of these 45 years added to the $\mathbf{4 0}$ of the base. The process is very slow as indicated by the $\Delta T$ of 126 years. The flex of the logistic, when growth is at its maximum, is quite late, around 1930. Apart from the "noise" due to a multiplicity of causes, no explicit breakthrough appears in the curve showing a progressive and cumulative process similar to the curve in Figure 1. 


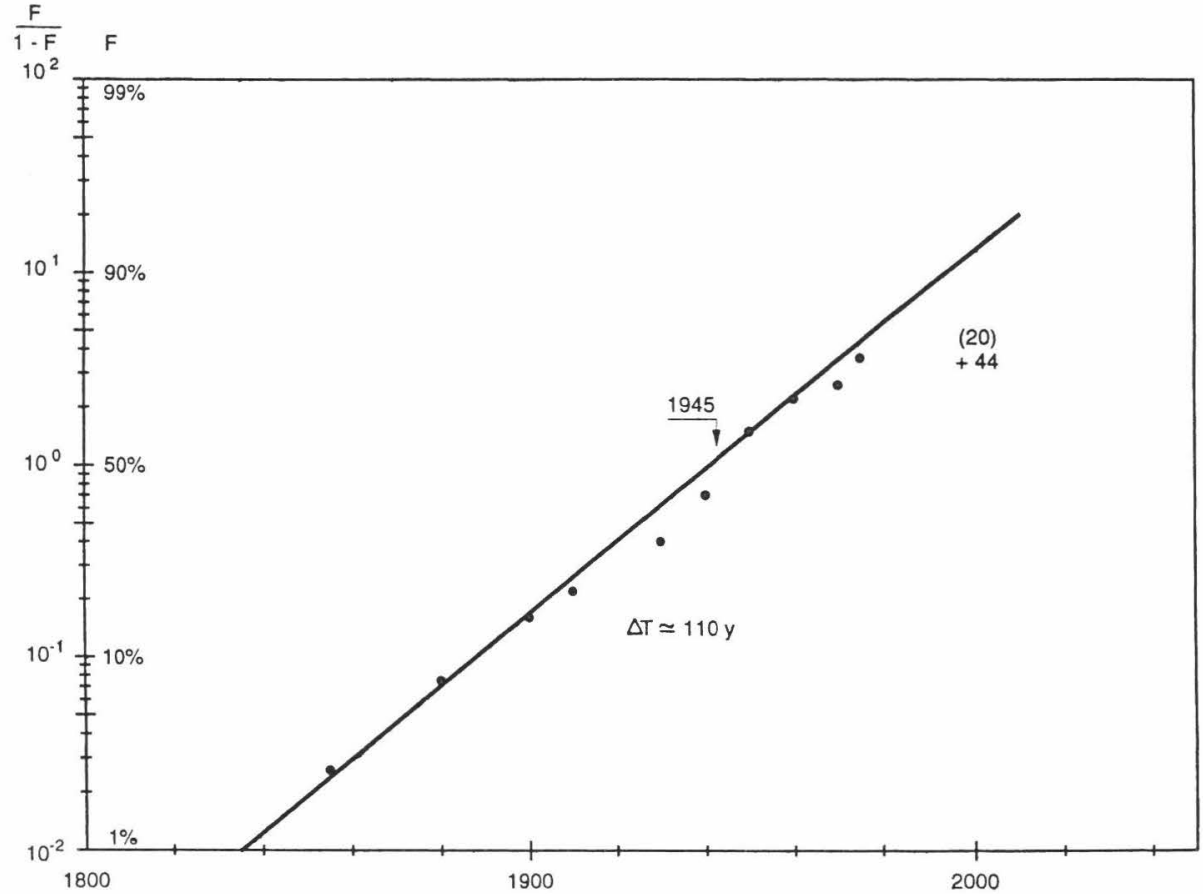

Fig. 4.

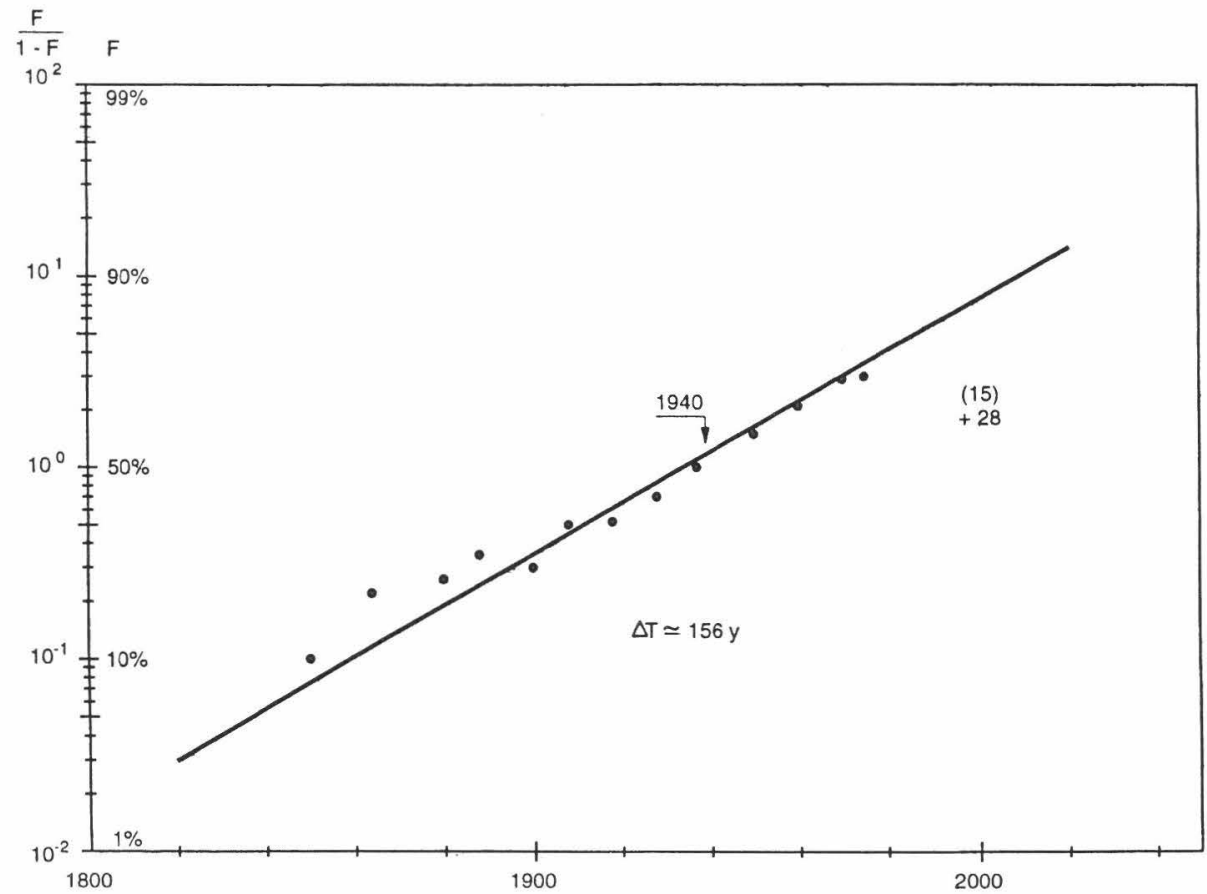

Fig. 5. 


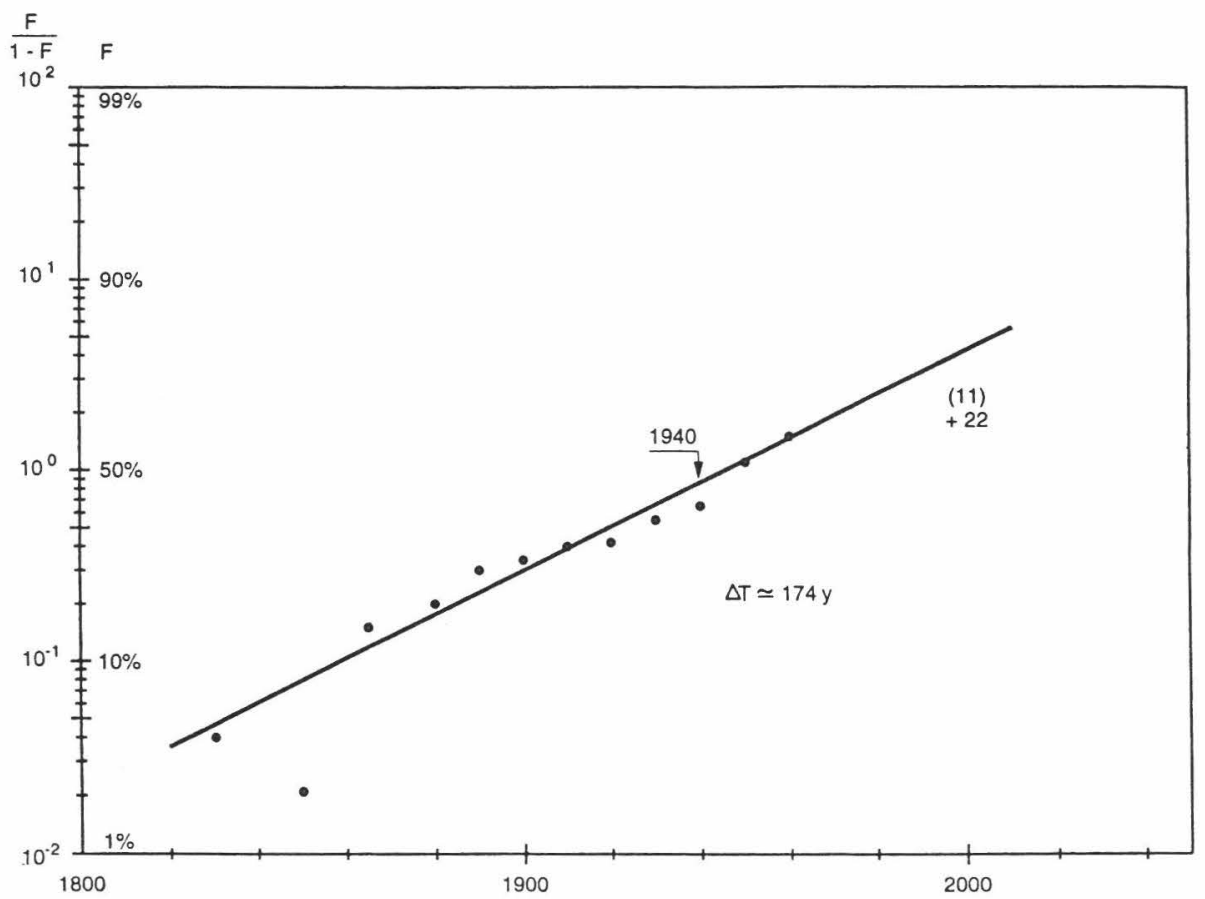

Fig. 6. Evolution of life expectancy at age 50 for Norwegian females. The dynamics of this increase in similar to that of 40 -year-old females. Life expectancy was 22 years in the 1800 s, and will reach $22+$ $11=33$ years in the next century. The point of maximum growth is again in 1940 , and the time constant is 174 years. Source: [7].

(Fisher-Pry transform [1]) is that S curve logistics are transformed into straight lines, and are more convenient to visualize and compare.

In Figure 1 all the parameters needed to identify the logistic equation are reported. The $\Delta \mathrm{T}$ gives an intuitive idea of the speed of the process. It reports the time between $\mathrm{F}=0.1$ and $\mathrm{F}=0.9$. The process must also be located in time (usually calendar time) and the center point of the logistic $(F=0.5)$ is dated. In Figure 1 the reference time is the age of the child, and 3.9 years is the age when the child controls $0.5 \times 2900=$ 1450 words approximately.

Armed with this very simple mathematical technique (see Appendix and references [2-5] for further details), let us look at how efficient the system is in removing the obstacles to the expression of longevity in large human populations. I have measured

Fig. 4. Evolution of life expectancy at age 20 for Norwegian females. The gain in life expectancy is again 20 years pointing to very low mortality between 10 and 20 years. Life expectancy in the early 1800 s was already 44 years for 20 -year-old females. Source: [7].

Fig. 5. Evolution of life expectancy at age 40 for Norwegian females. The increase in life expectancy obviously decreases with age. At age 40 it is 15 years at saturation, which will occur after the year 2000. Life expectancy in the 1800 s was already 28 years. The increase has been very slow, with a time constant of $\Delta T=156$ years and the center point quite late, in 1940. Source: [7]. 


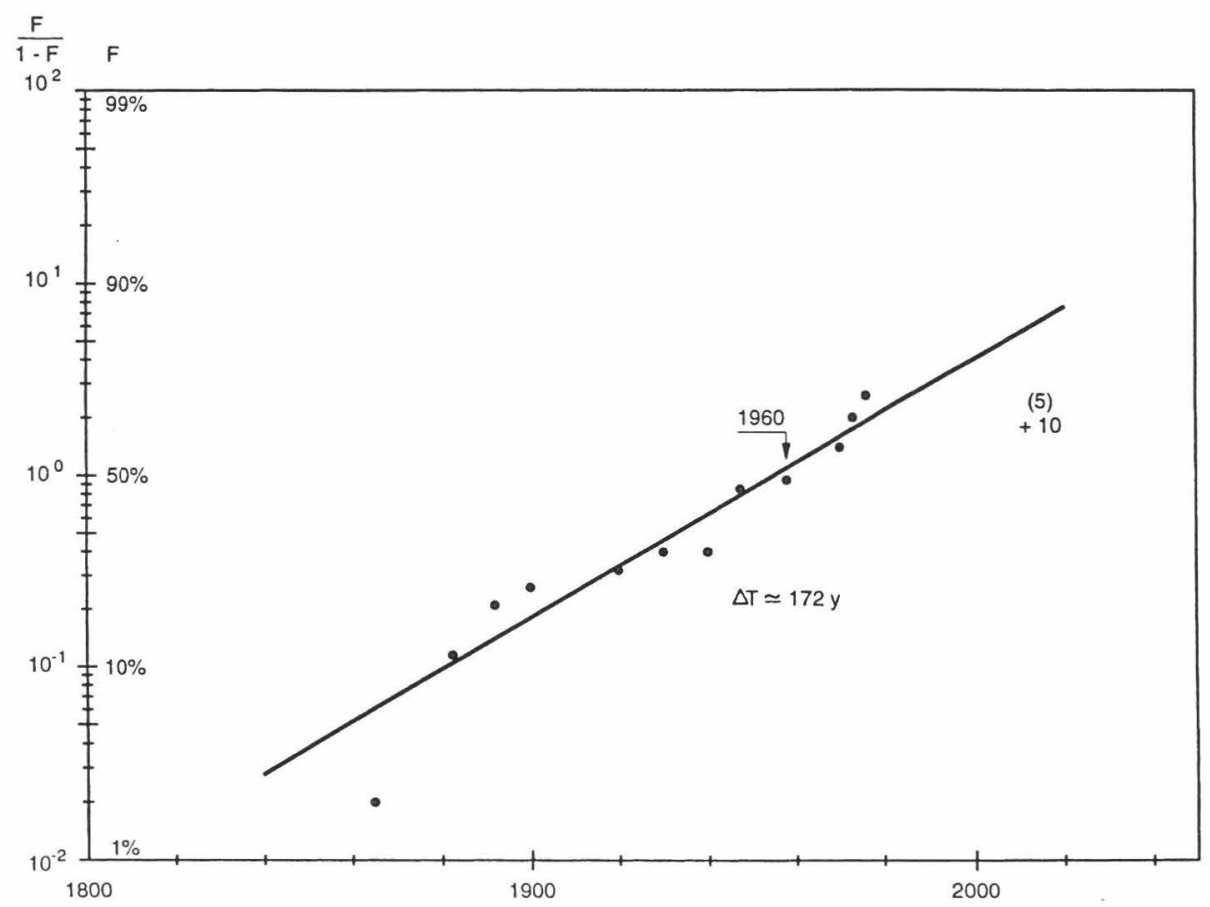

Fig. 7. Evolution of life expectancy at age 70 for Norwegian females. With rising age, the historical improvement in life expectancy occurs later and later in time. Here the center point is 1960. The life expectancy in the 1800 s was $70+10=80$ years. Three extra years have been added to date, and another two years will be added in the next century with a final expected age at death of $70+10+5$ years $=$ 85 years. Source: [7].

the historical evolution of life expectancy. Figure 2 reports the analysis of life expectancy at birth for Norwegian females. To read this figure another consideration must be added. The growth in life expectancy starts from a historical platform which for this case has been calculated to be about 40 years. The learning process adds another 45 years (reported in parenthesis). In other words, the logistic curve starts from a lower level of 40 years and grows to 85 years as the upper asymptote.

At this time (1993) the logistic reaches $90 \%$ of its final value. Actually the life expectancy at birth of Norwegian females is now $0.9 \times 45+40=80.5$ years. On the basis of the evolution of current health technologies, four additional years should be added during the next 50 years. It must be clear that miscellaneous causes of death are included (such as car accidents), which do not seem to decrease in time. The reason for the 50 years to get merely four extra years of life is that the process has always been very slow (126 years to go from $F=0.1$ to $F=0.9$ ) and is near saturation. We are slowly scraping, so to speak, the bottom of the barrel. The center of the logistic, when speed of growth in life expectancy was at a maximum, is 1930. This rules out quantum leaps in medicine, such as the discovery of antibiotics, as the cause for the increase. Apart from a certain amount of "noise," the evolution of life expectancy is always smooth (i.e., it does not show kinks related to special events in medicine or hygiene).

\section{Results}

The analysis can be repeated looking at the increase in life expectancy at various ages. I have analyzed the life expectancy at ages 10, 20, 40, 50, 70, and 80 for Norwegian 


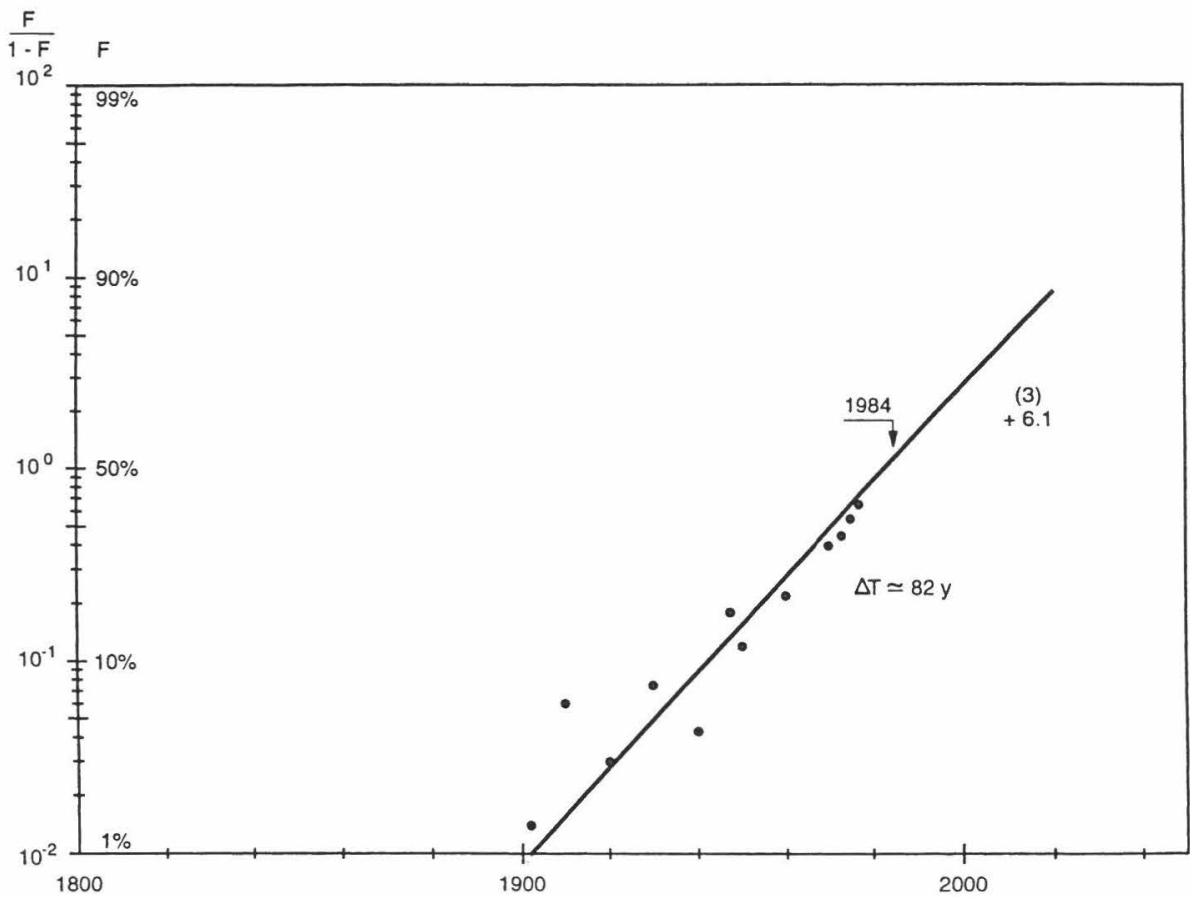

Fig. 8. Evolution of life expectancy at age 80 for Norwegian females. Progress seems to be relatively fast, with a time constant of only 82 years, but quite late with a central point in 1984 . The gain in life expectancy has been less than two years, to date, with the hope of another year in the middle of the next century. These analyses are at the level of the population which may dim some special individual successes. Source: [7].

females. The results are reported in Figures 3 to 8. That the largest increase in life expectancy is linked to reduced child mortality is well illustrated in the current literature. Other ages have not been examined as thoroughly. Increase in life expectancy at age 10 has been 20 years; at age 20, again 20 years; at age 40, 15 years; at age 50, 11 years; at age 70, 5 years; and at age 80,3 years. In spite of the progress of gerontology, 70 year-olds will add only five years of life and that spread over a time span of about two centuries. To date about $60 \%$ of these five years or about three years has actually been achieved. Current literature about the marvels of medicine for seniors might be

TABLE 1

Increase in Life Expectancy of Norwegian Women

\begin{tabular}{|c|c|c|c|c|c|}
\hline Age & $\begin{array}{l}\text { Life expectancy } \\
\text { in } 1800 \\
\text { (years) }\end{array}$ & $\begin{array}{l}\text { Years } \\
\text { added }\end{array}$ & $\begin{array}{c}\Delta \mathrm{T} \text { of process } \\
\text { (years) }\end{array}$ & $\begin{array}{l}\text { Middle } \\
\text { point }\end{array}$ & $\begin{array}{c}\text { Calculated final } \\
\text { value for life } \\
\text { expectancy } \\
\text { (years) }\end{array}$ \\
\hline 0 & 40 & 45 & 126 & 1930 & 85 \\
\hline 10 & 52.5 & 20 & 81 & 1945 & 82.5 \\
\hline 20 & 44 & 20 & 110 & 1945 & 84 \\
\hline 40 & 28 & 15 & 156 & 1940 & 83 \\
\hline 50 & 22 & 11 & 174 & 1940 & 83 \\
\hline 70 & 10 & 5 & 172 & 1960 & 85 \\
\hline 80 & 6.1 & 3 & 82 & 1984 & 89.1 \\
\hline
\end{tabular}




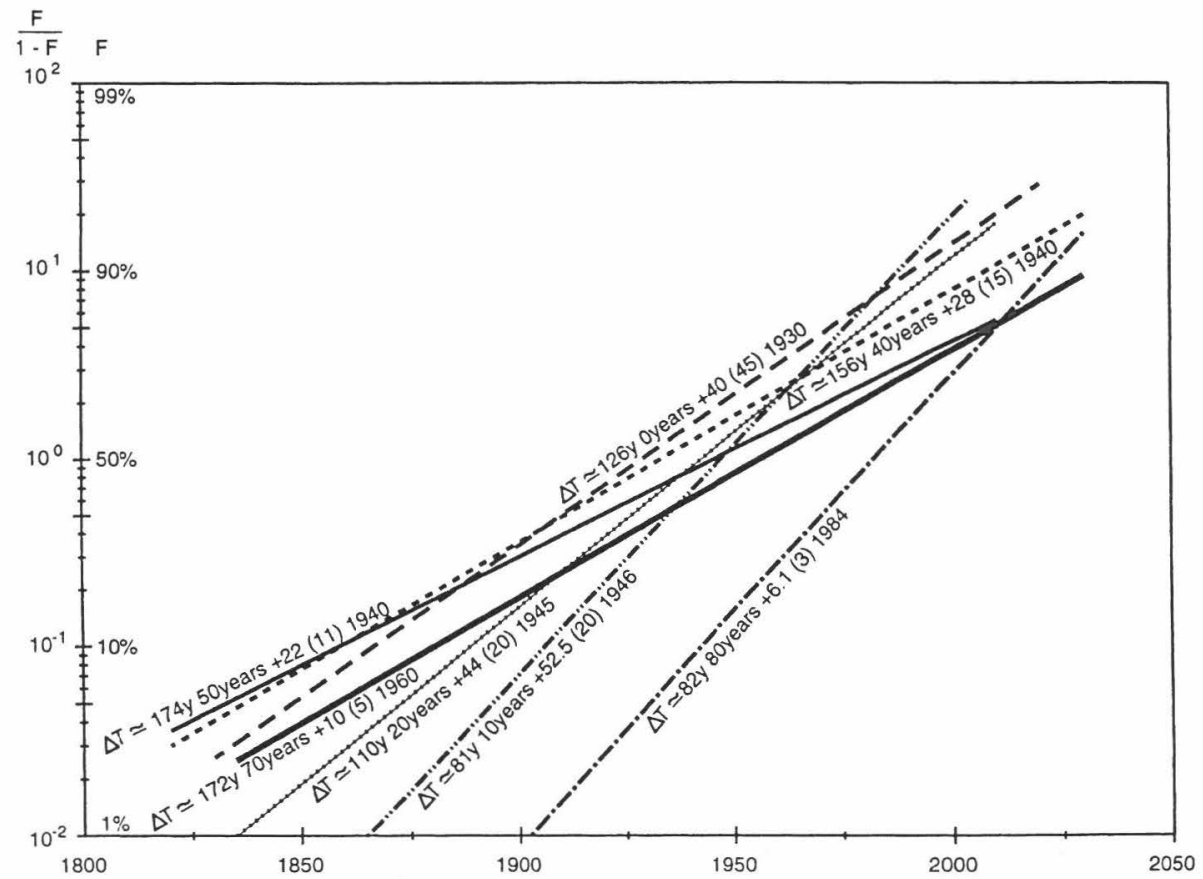

Fig. 9.

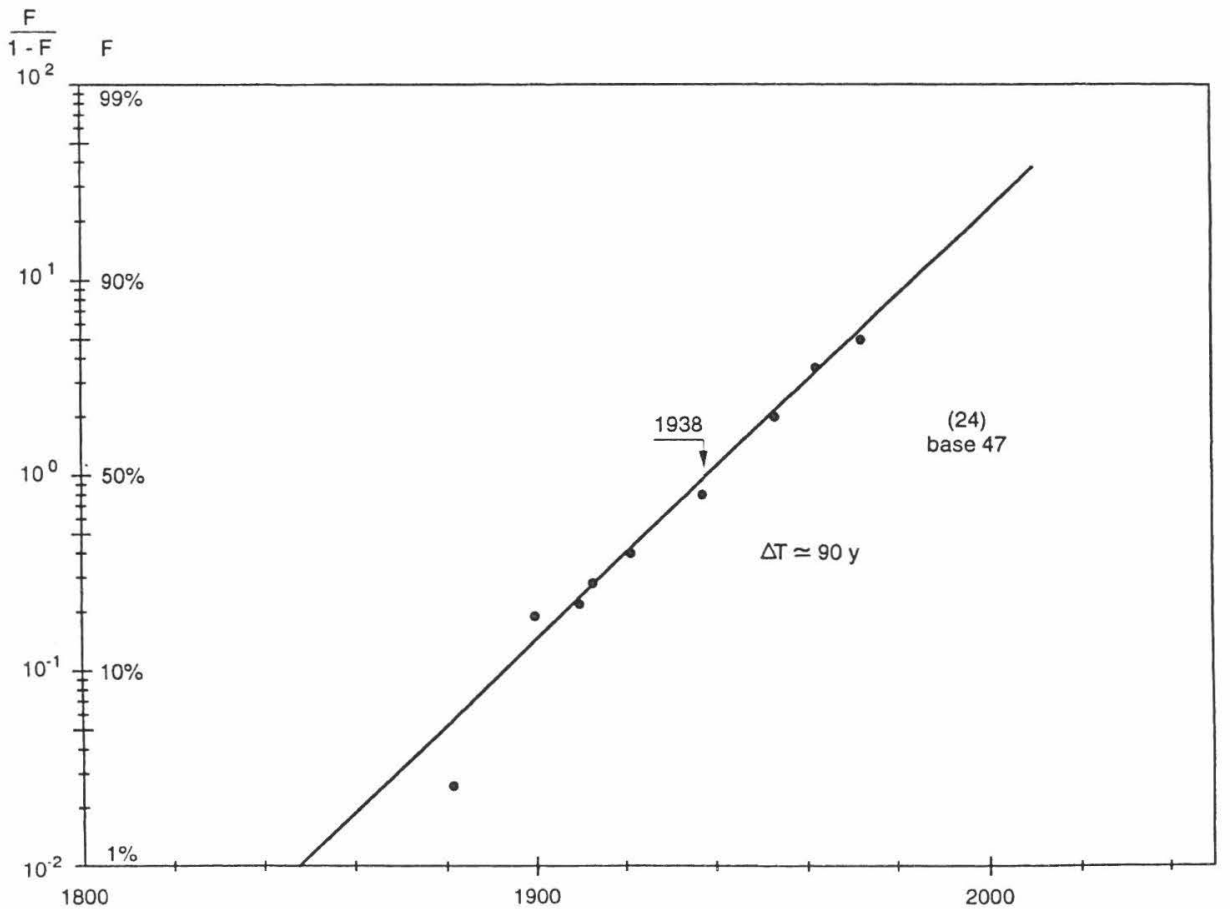

Fig. 10. 
$\frac{F}{1-F} \quad F$

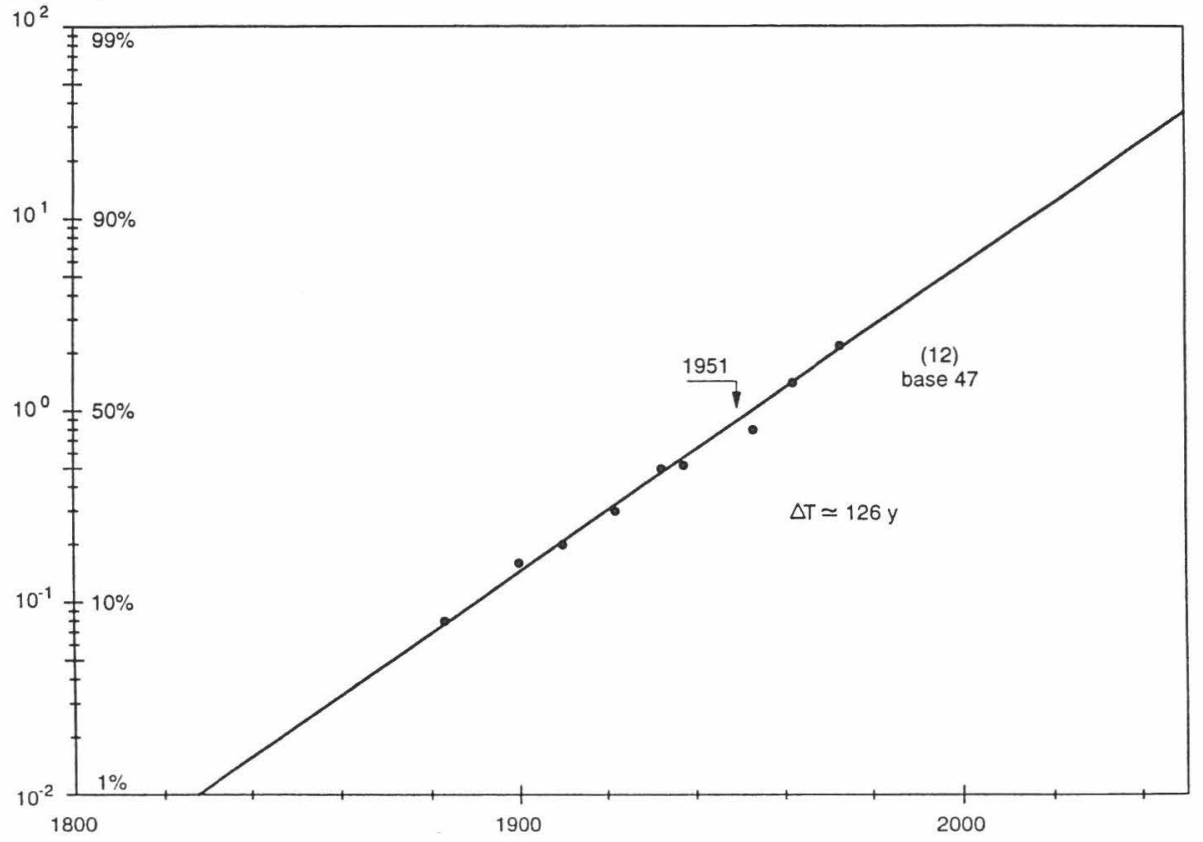

Fig. 11. Evolution of life expectancy at age 60 for Italian females. In 1800, Italian females had a life expectancy at age 60 of about 12 years. Another 12 years is added at saturation of the life expectancy increase. They have already achieved about nine years. The total $(60+12+12=84)$ brings their final expected age at death close to that of Norwegian females. Source: [7].

misleading. Medicine and health practices may have been good moderators for old age, but seem to have added very little to the length of old people's life. Medicine and health practices have actually carried more young people into the gray melting pot.

As can be seen in Figure 8 , life expectancy at age 80 will be increased, at saturation, by about three years over a time span of about a century. Half of these three years have already been achieved, the other half will be realized before 2050. It is interesting to note that the point of maximum growth of life expectancy for this age group was in 1984. The +6.1 in the figure means that in 1900 , 80 -year-old females in Norway had

Fig. 9. Evolution of life expectancy at various ages for Norwegian females: A synoptic view. The results reported in Figures 2-8 are compared. One important point is that the process of increasing life expectancy is nearing saturation at all ages. As reported in Table 1, most people will die old, and life expectancy for Norwegian females converge around 84 years. There is obviously a statistical distribution around this value and the number of centenarians will increase as the consequence of so many people having reached 80 years of age, protected from the stumbling blocks expected by the generations of the last century. Source: [7].

Fig. 10. Evolution of life expectancy at age 10 for Italian females. The results of this analysis are not substantially different from those of Norwegian females of the same age, confirming the soundness of the results. Social conditions and quality of data can be quite different between Northern Europe and Southern Europe. Norwegian females had a higher life expectancy in 1800 (52.5 versus 47 years) but Italian women have caught up ( +24 years versus +20 years). The central point and time constant for the increase are basically the same. Source: [7]. 
$\frac{F}{1-F} \quad F$

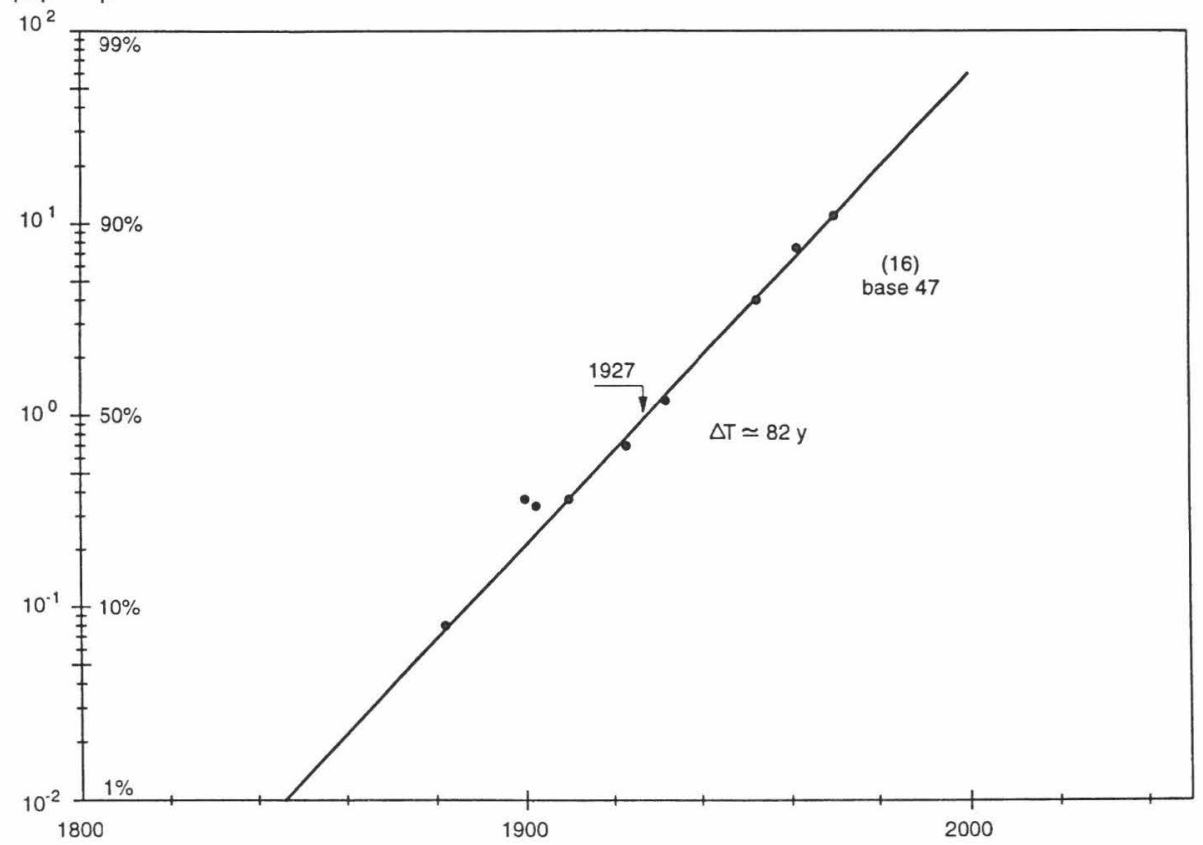

Fig. 12. Evolution of life expectancy at age $\mathbf{1 0}$ for Italian males. It is interesting to note that in the early 1800 s Italian males and females had the same life expectancy of 47 years at age 10 . But females have achieved a larger increase since then ( 24 years versus 16 years, at saturation). The taxonomy of the process is quite similar. Males realized the increase in life expectancy earlier and faster, but this increase was lower than the increase for females. Source: [7].

a life expectancy of 6.1 years. This life expectancy grew to 7.7 years in 1990 . This is an improvement, but certainly not a spectacular one. One can wryly speculate if the high costs to the individual and to society of pampering the increasing number of the elderly are really worth the effort.

The numerical results of this survey of Norwegian females have been condensed in Table 1. Because the values of the parameters have been calculated by fitting the data with logistics, there is a certain amount of imprecision incorporated that leads to some inconsistencies when they are taken together. In particular, the values of life expectancy at 0 years and 10 years do not match a continuous series. Infant mortality is a phenomenon that should be studied separately, and I will return to this topic later in this article.

The most interesting aspect of the table is that life expectancy at all ages leads to a figure of about 84 years ( \pm 1 year), which I take as the definition of longevity. This is the mean value for Norwegian females, naturally. Actually, handling these statistics I got the suspicion that a small percentage of the population, some $5 \%$ maybe, has a value for longevity of about 100 years.

A second message can be read from Table 1. In spite of the explosion of medical know-how and practices in the last 30 years there has been no change in the long-term evolution process of life expectancy, which seems intrinsically very long term with time constants in the range of centuries. Furthermore the point in time where progress was fastest was in the 1930s, except for gerontology which accelerates much later. The data 


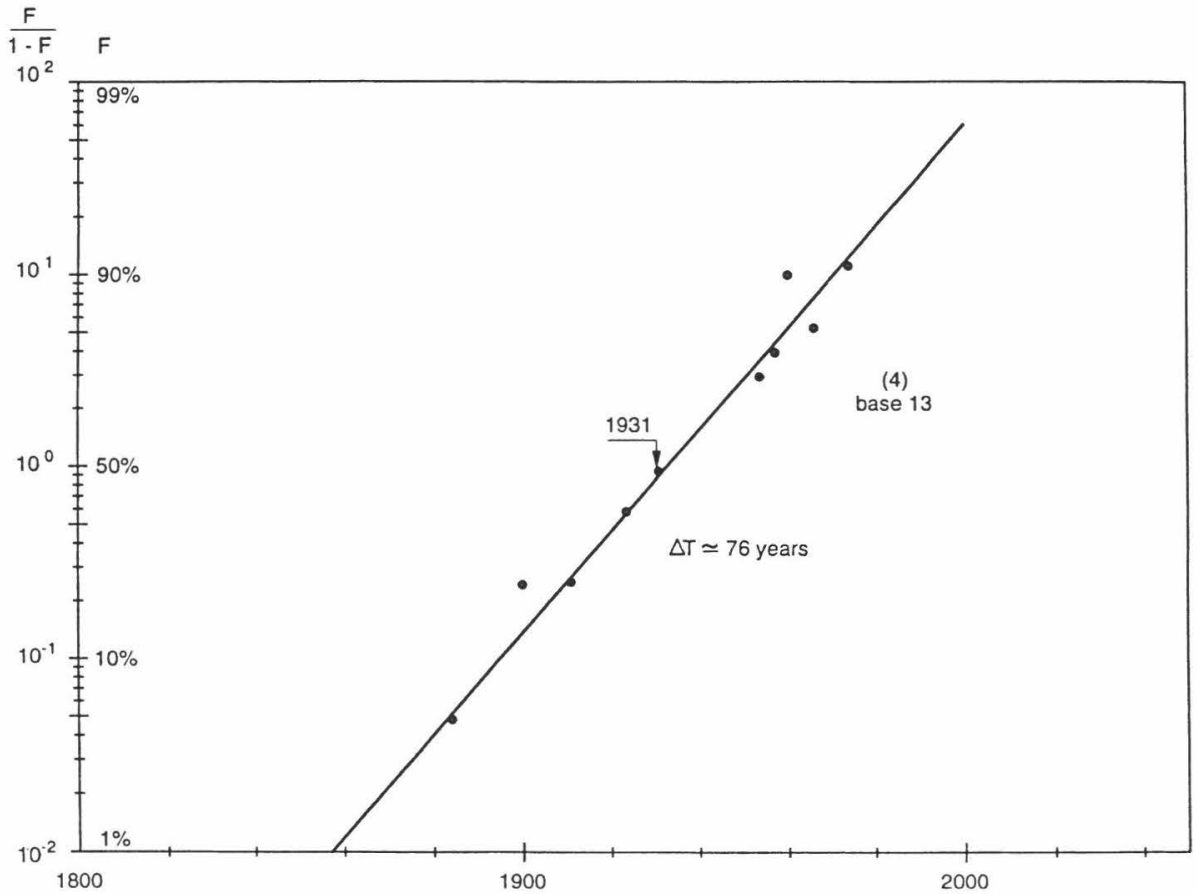

Fig. 13. Evolution of life expectancy at age 60 for Italian males. At age 60 in 1800 Italian males had a slightly higher life expectancy than females. According to our extrapolation they will finally die at an earlier age than females (by five years). Males have already realized 3.5 years (out of 4), and females have achieved about 7 years (out of 12). Source: [7].

from Table 1 are reported in Figure 9, where all the figures are combined for comparison. It is clear from this synoptic chart that life expectancy at all ages is approaching longevity. The next step might be to increase longevity through genetic engineering or equivalent practices. Biomedical research is actually moving in this direction.

The reason for choosing Norway as a test case to check a methodology is that the place is quiet and isolated, which is a good starting point. More complicated situations may be easier to disentangle if one has a solid reference.

In the case of Italy, life expectancy of males and females, at ages 10 and 60, are reported in Figures 10 to 13. Life expectancy was the same for males and females only at the beginning of the $1800 \mathrm{~s}$, both at age 10 and at age 60 . But the longevity of women at birth has increased more, up to the 84-year level (still not reached) of the Norwegian females.

This type of analysis and this form of presentation are very suitable for making international comparisons that may be used to study cultural, ecological, and economic effects. Some examples are reported in Figures 14 and 15. There is much room for reflection. It is curious, for example, that the evolution of life expectancy for women is so homogeneous in Europe; in contrast with men's life expectancy which is linked to actual nationality. The increase in life expectancy with age also presents a striking regularity and is reported in Figure 16 for Dutch women.

In the last part of the article I focus on infant mortality. The analysis is done using the same methodology, but I look at the process in reverse, at the secular reduction of mortality (during the first year after birth). One starts from a historical mortality calcu- 

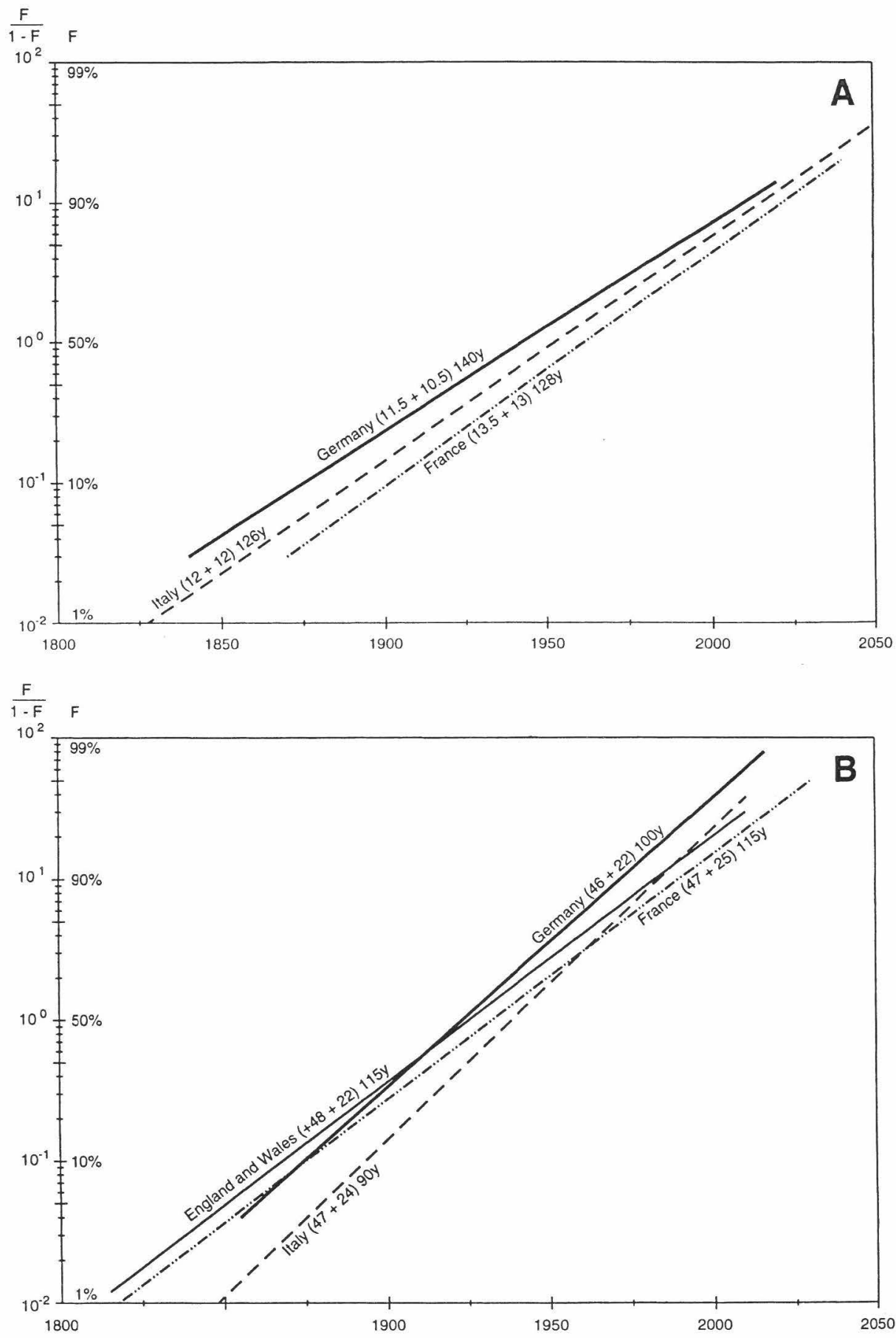

Fig. 14. (A) Evolution of life expectancy at age 10 for females in England and Wales, France, Germany, and Italy. This figure confirms the substantial homogeneity in the evolution of life expectancy for European females, independently of nationality, although some differences persist in the final value of longevity. The numbers in parenthesis represent life expectancy around 1850, and the years added at the end of the increase (saturation) as calculated through the fitting logistic equation. Source: [7]. 
TABLE 2

Equation Parameters for the Cases Analyzed and Not Reported in the Text

\begin{tabular}{llccccc}
\hline Country & Age (Sex) & Base & $\begin{array}{c}\text { Years } \\
\text { added }\end{array}$ & $\begin{array}{c}\Delta \text { T } \\
\text { (years) }\end{array}$ & $\begin{array}{c}\text { Center } \\
\text { point }\end{array}$ & $\begin{array}{c}\text { Calculated } \\
\text { longevity }\end{array}$ \\
\hline Denmark & $10(\mathrm{M})$ & 47.0 & 15 & 75 & 1908 & 72 \\
& $70(\mathrm{M})$ & 7.7 & 3.5 & 120 & 1915 & 81.2 \\
Sweden & $80(\mathrm{M})$ & 4.5 & 2.1 & 110 & 1943 & 86.6 \\
England and Wales & $10(\mathrm{M})$ & 43.5 & 21.5 & 144 & 1906 & 75 \\
& $60(\mathrm{M})$ & 11.5 & 6.5 & 135 & 1890 & 78 \\
France & $10.0(\mathrm{M})$ & 45 & 17.5 & 107 & 1911 & 72.5 \\
& $10(\mathrm{~F})$ & 48.0 & 22 & 115 & 1927 & 80 \\
& $10(\mathrm{M})$ & 47.0 & 14 & 80 & 1923 & 71 \\
Germany & $60(\mathrm{M})$ & 13.25 & 5 & 130 & $\sim 1960$ & 78.25 \\
& $10(\mathrm{~F})$ & 47.0 & 25 & 115 & 1933 & 82 \\
& $60(\mathrm{~F})$ & 13.5 & 13 & 128 & 1965 & 86.5 \\
& $10(\mathrm{M})$ & 45.0 & 15.5 & 70 & 1915 & 70.5 \\
Finland & $60(\mathrm{M})$ & 11.8 & 4 & 60 & 1915 & 75.8 \\
& $10(\mathrm{~F})$ & 46.0 & 22 & 100 & 1915 & 78 \\
& $60(\mathrm{~F})$ & 11.5 & 10.5 & 140 & 1943 & 82 \\
& $10(\mathrm{M})$ & 47.0 & 16 & 82 & 1927 & 73 \\
& $60(\mathrm{M})$ & 13.0 & 4 & 76 & 1931 & 77 \\
& $10(\mathrm{~F})$ & 47.0 & 24 & 90 & 1938 & 81 \\
& $60(\mathrm{~F})$ & 12.0 & 12 & 126 & 1951 & 84 \\
& $10(\mathrm{M})$ & 48.0 & 15 & 115 & 1950 & 73 \\
& $50(\mathrm{M})$ & 19.6 & 4 & 96 & 1965 & 73.6 \\
& $10(\mathrm{~F})$ & 49.5 & 20 & 61 & 1949 & 79.5 \\
& $50(\mathrm{~F})$ & 20.0 & 10 & 120 & 1950 & 80 \\
\hline
\end{tabular}

lated by extrapolating backward and descends logistically toward a lower value very close to zero. The analysis is reported both in linear coordinates and in the Fisher-Pry transform that linearizes logistics (Figure 17).

The effect of World War II is clear and appears to stop the reduction in mortality for a period of five or six years. World War I does not seem to have had any effect. The deviation of World War II is, however, reabsorbed and has no influence on the secular decrease of this mortality. The same analysis is reported for Norway and France (Figures 18 and 19). The historical maximum calculated backward and reported in parentheses corresponds to a period in the early 1800s. The actual values are between 150 and 250 deaths per 1000 infants, much lower than infant mortality in primitive populations. Therefore, there must have been a previous pulse of infant mortality decrease, for which I did not find reliable statistical time series to make a detailed study.

The last segment I touch on is the period between conception and birth. Conception should be the discontinuity appropriate to start measuring life, as it is done, for example,

(B) Evolution of life expectancy at age 60 for German, Italian, and French females. It is interesting to compare different nations to see possible climate, nutritional, and genetic effects on life expectancy. This comparison of women at age 60, however, shows few differences in the final value of life expectancy at age 60 (22 years for German females, 24 for Italian females, and 26.5 for French females). The taxonomy of the process is almost identical in the three cases, with time constants of 140 years, 126 years, and 128 years, respectively. Source: [7]. 

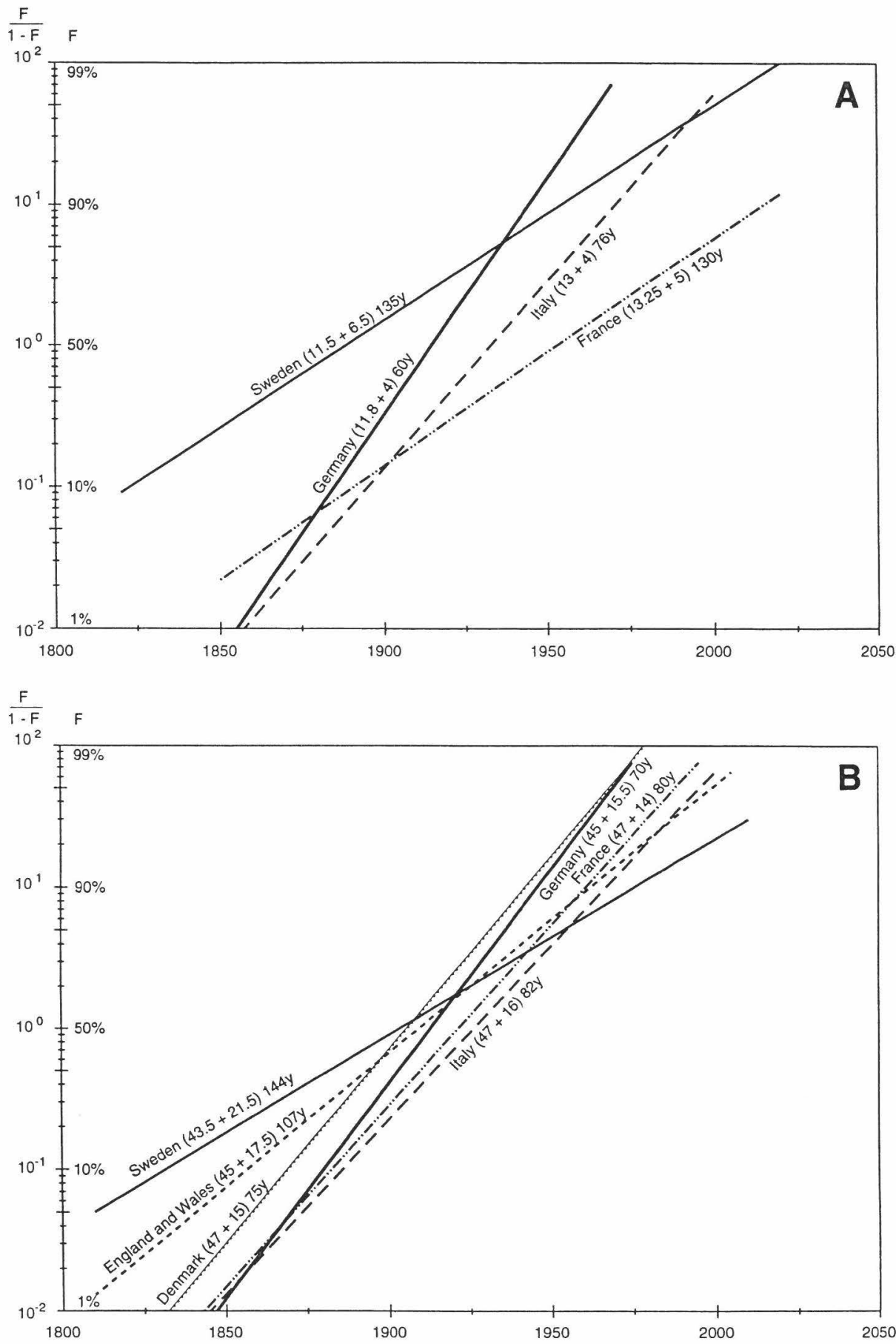

Fig. 15. (A) Evolution of life expectancy at age 10 for males in Sweden, England and Wales, Denmark, Italy, Germany, and France. With the exception of Sweden, the taxonomy appears more homogeneous at age 10 than at age 60 . The first number in parenthesis represents life expectancy at age 10 around 1850 and the second number the years added at saturation. Source: [7]. (B) Evolution of life expectancy at age 60 for Swedish, German, Italian, and French males. In this case the taxonomy 


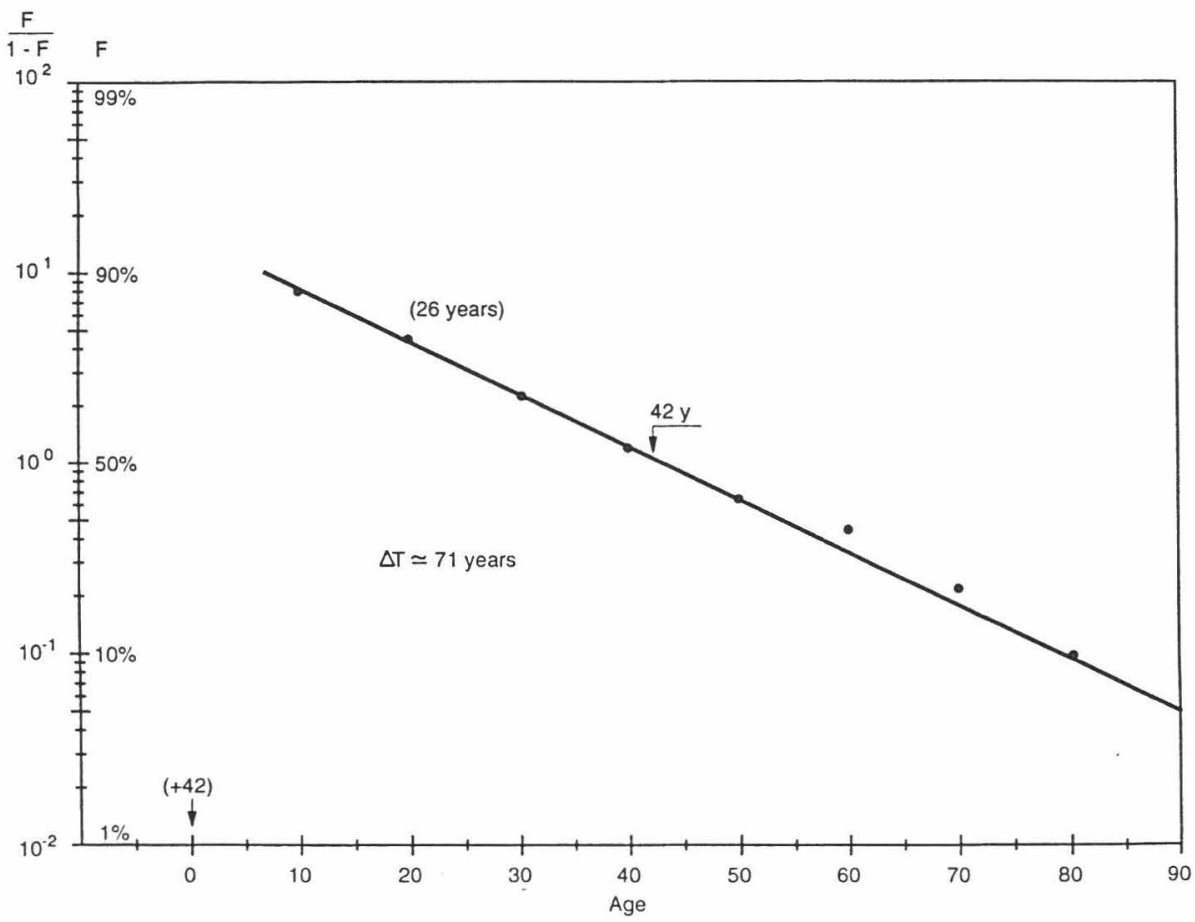

Fig. 16. Final increase in life expectancy at different ages for Dutch women. The chart reports the final gain in life expectancy as a function of age. This gain decreases logistically as a function of age, with a calculated virtual maximum of 26 years. But the increase in life expectancy at age zero is 42 years. This discrepancy points to a different mechanism for the increase in life expectancy of infants, providing the extra 16 years. The quality of the fitting for ages $\mathbf{1 0}$ and above is remarkable and may permit the estimation of the increase in life expectancy at age 90 and 100, where statistics are not reported in our source. Source: [7].

in Southeast Asia. But this way of counting reveals some surprises. Prenatal mortality in a country like the United States where abortion is accepted, legally and socially, is estimated to be about $50 \%$, close to infant mortality in primitive populations. Consequently life expectancy at conception is about the same in both cases. There is something futile in the machinery of medicine progress.

The results reported in this article are a selection from a much broader analysis that has been done for which the parameters of the fitting equation are reported in Table 2 .

\section{Discussion}

A very simple logistical model, originally used for the study of the growth of animal populations in the niche, and also for the propagation of epidemics, has been used here to describe a learning process: that of preserving human life.

of the increase in life expectancy is very different for various nations. Final life expectancy at age 60 will be $\mathbf{1 8}$ years for Swedes, $\mathbf{1 5 . 8}$ for Germans, $\mathbf{1 7}$ for Italians, and $\mathbf{1 8 . 2}$ for the French. Apart from the Swedes, Germans, Italians, and French are in the same order for longer life expectancy as the females. Source: [7]. 

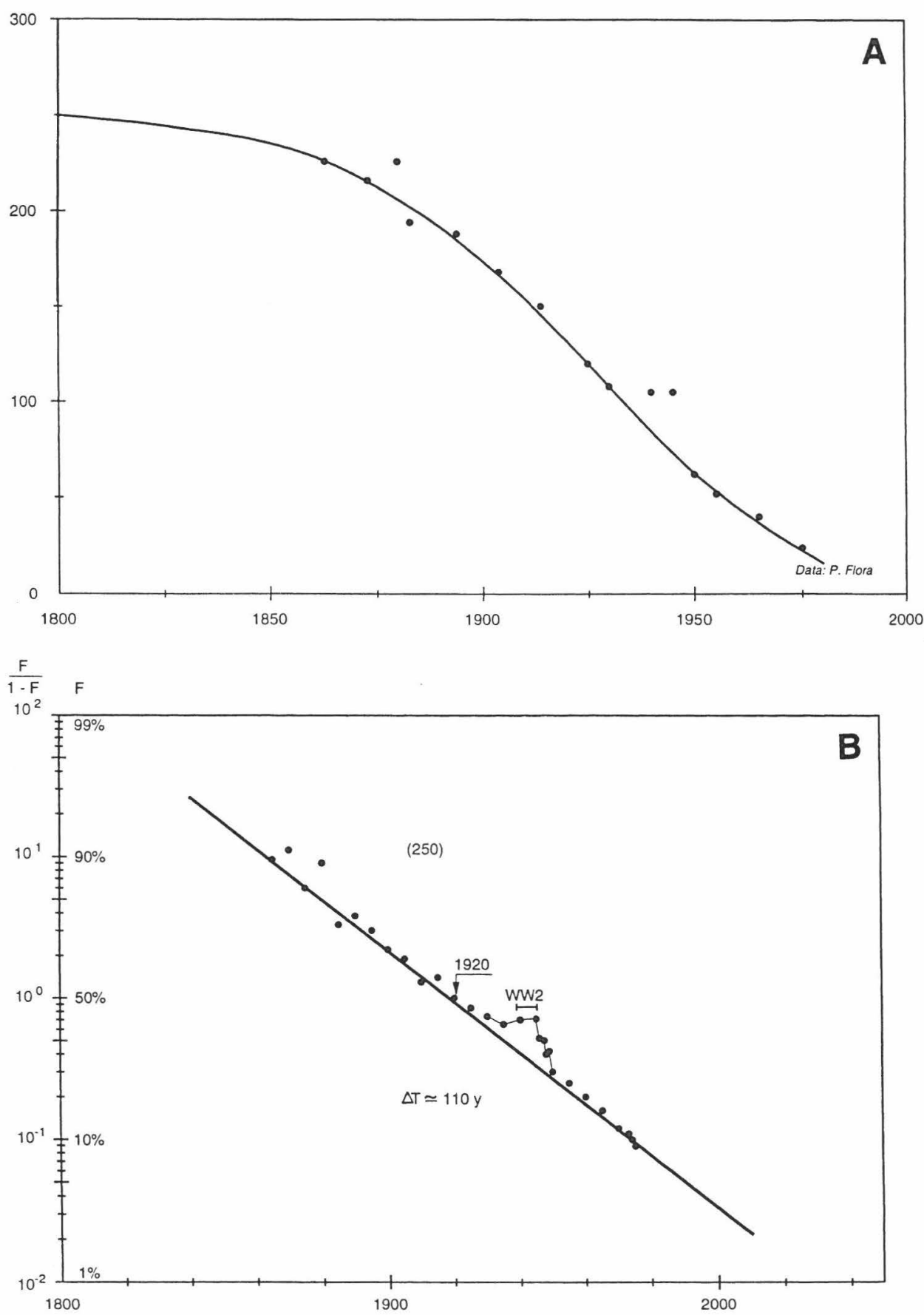

Fig. 17. Italy: Evolution of infant mortality. The particular position of infant (up to 1 year) mortality in determining life expectancy as suggested by the analysis reported in Figure 16, prompts a special analysis on the subject. The mathematics is the same, but in this case we chose to measure mortality starting from the high values (extrapolated) in the early 1800s, and then look at its decrease in time. (A) Presents the data in linear form, giving infant deaths per 1000 infants from 1860 to 1975 . The shape is clearly that of a logistic $S$ curve, more crisply represented in (B) using the Fisher-Pry transform. For 


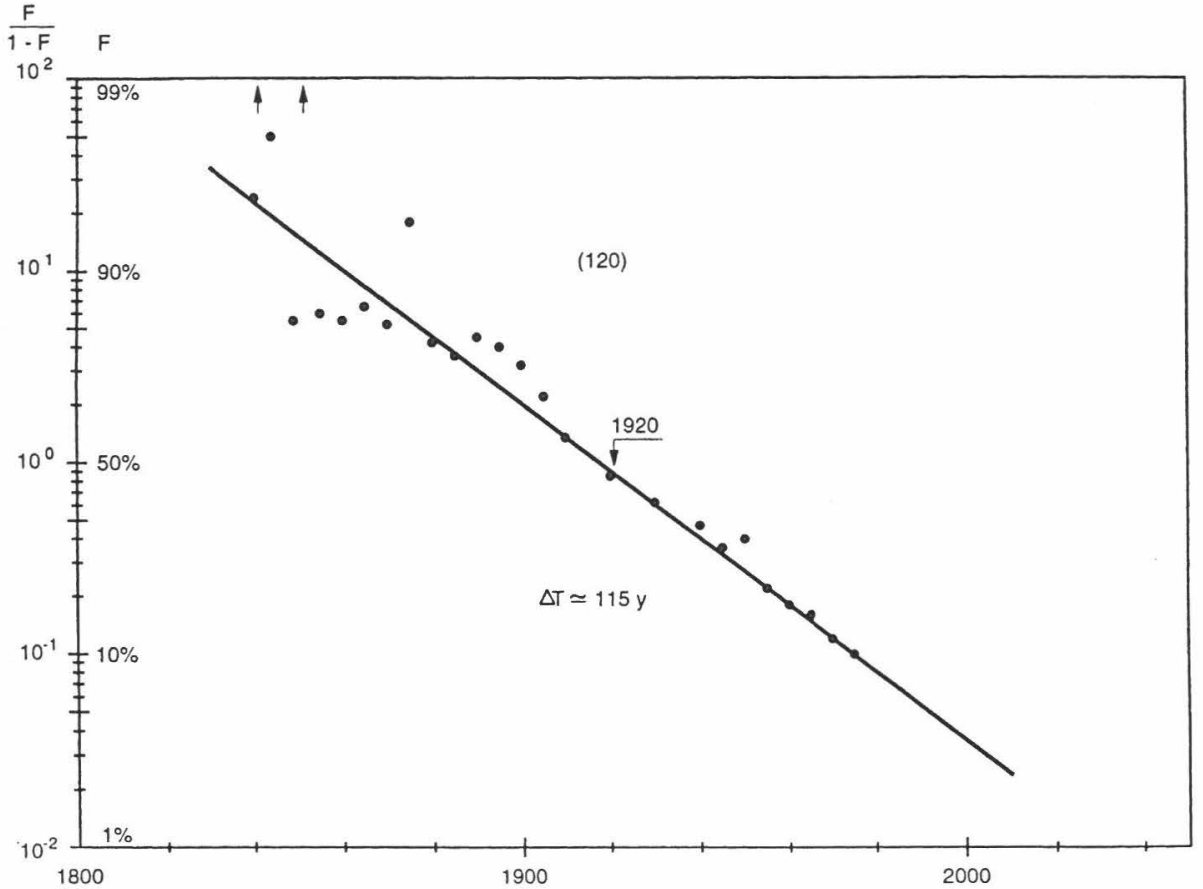

Fig. 18. Norway: Evolution of infant mortality. The central point in the decrease of infant mortality is again in the 1920s and the time constant is very similar to the Italian one. There is no apparent effect from World War II. The starting level, 120 deaths per 1000 infants is half the Italian one, but the taxonomy of mortality decrease is almost the same. Source: [7].

This kind of modeling is phenomenological, that is, it stops at the description of facts, but as in the various thousands of cases we applied it for technical and social learning, it reveals an astonishing consistency in the long-term behavior of the system. It shows the approaching end of the long march to eliminate the causes of death preventing life expectancy to reach the fulfillment of longevity.

Note: Figure 19 appears on following page.

\section{References}

1. Fisher, J. C., Pry, R. H.: A Simple Substitution Model of Technological Change, Technological Forecasting and Social Change 3, 75-88 (1971).

2. Lotka, A.: Elements of Physical Biology. Republished 1956 as Elements of Mathematical Biology, Dover Publications, New York, 1924.

3. Marchetti, C.: Society as a Learning System-Discovery, Invention, and Innovation Cycles Revisited, Technological Forecasting and Social Change 18, 267-282 (1980).

4. Kingsland, S.: The Refractory Model: The Logistic Curve and the History of Population Ecology, The Quarterly Review of Biology March, 57 (1982).

Italy, the base mortality is $\mathbf{2 5 0}$ deaths per 1000 infants and decreases to a final calculated value of $\mathbf{2 . 5}$ deaths per 1000 infants around 2020. Half of this decrease was reached by 1922 . The decrease stopped for a few years during World War II to resume later the previous course. There is no apparent effect from World War I. Source: [7]. 


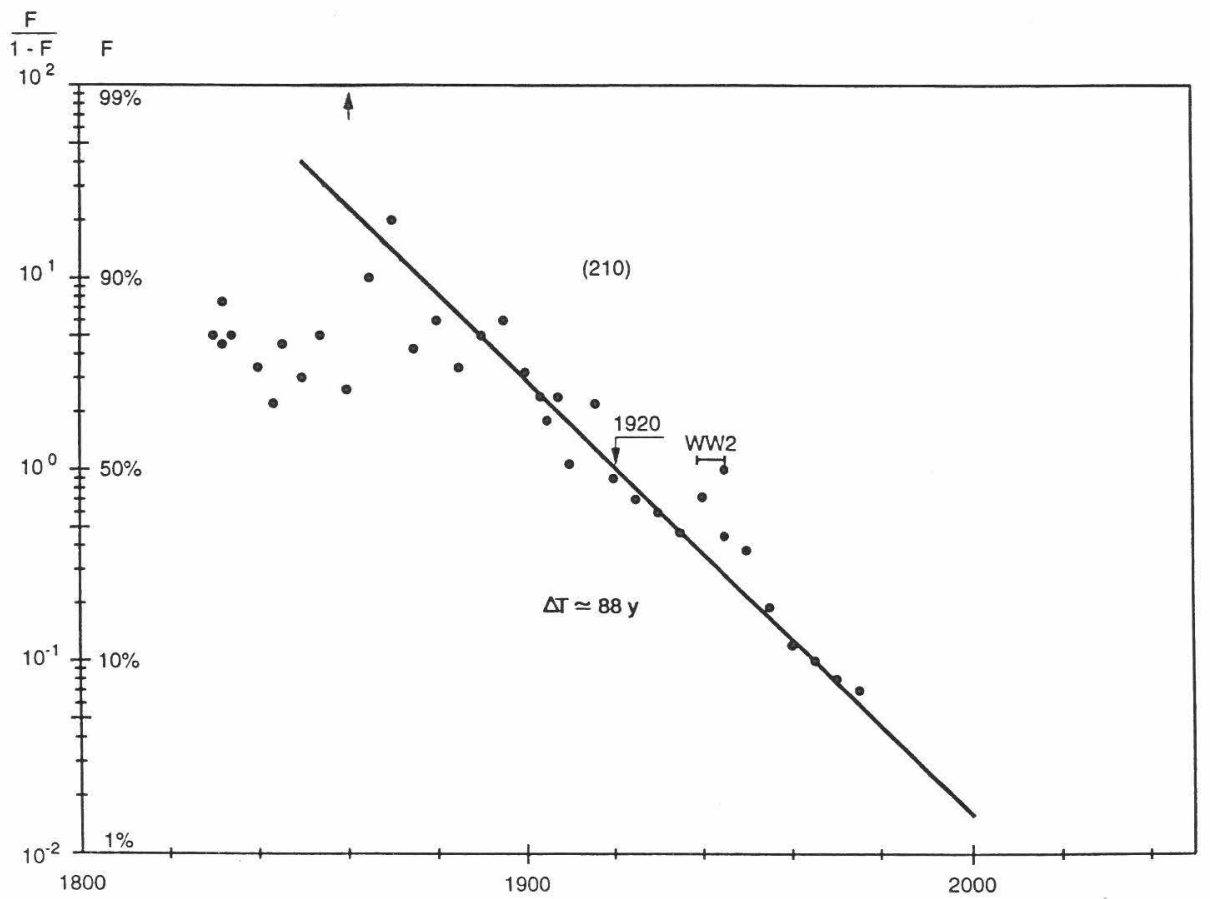

Fig. 19. France: Evolution of infant mortality. The starting level of mortality is not much different from the Italian level, 210 deaths per 1000 infants round 1800, and again the taxonomy is similar. The central point, 1920, is identical with the Italian and Norwegian one, but the time constant is shorter. The significant effect of World War II is remarkable. Source: [7].

5. Montroll, E. W.: Social Dynamics and the Quantifying of Social Forces, Proc. Natl. Acad. Sci. USA 75, 4633-4637 (1978).

6. Markey, J. F.: The Symbolic Process, K. Paul, London, 1928.

7. Flora, P.: State, Economy, and Society in Western Europe, 1815-1975. Campus Verlag, Frankfurt, 1983.

Received 19 November 1995; accepted 8 January 1997

\section{Appendix}

The mathematics used in this analysis is extremely simple. We add this note for those not familiar with it. The basic concept of epidemic diffusion is condensed in the epidemic equation:

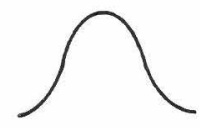

$$
d N=a N(\bar{N}-N) d t
$$

saying that the number of new adopters $(d N)$ during time $d t$ is proportional $(a)$ to the number of actual adopters $(N)$ multiplied by the number of potential adopters $(\bar{N}-$ $N$ ), where $\bar{N}$ is the final number of adopters.

The integration of this equation gives 


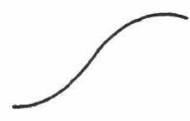

$$
N=\bar{N} /[1+\exp -(a t+b)]
$$

which is the expression of a logistic S-curve well known to epidemiologists and demographers. We apply it to ideas.

In the figures of the present paper the logistic equation is presented in an intuitively more pregnant form. $N$ is measured in relative terms as fraction of $\bar{N}(F=N / \bar{N})$, and the $S$-curve is "straightened" by plotting $\log (F / 1-F)$ (Fisher-Pry transform).

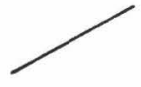

$$
\log (F / 1-F)=a t+b
$$

The time constant $\Delta T$ is the time to go from $F \simeq 0.1$ to $F \simeq 0.9$. It takes the central part of the process $(80 \%)$ and the relation between $\Delta T$ and the $a$ in the equation is $\Delta T=4.39 / a$.

The central date $T_{0}$ is defined as b/a.

The final number of adopters $\bar{N}$ is given as a number in parenthesis. 
NORTH-HOLLAND

\section{Announcement}

\section{1st International Conference on}

Technology Policy and Innovation

July 2-4, 1997, University of Macau, Macau

This Conference is designed to discuss aspects related to science and technology systems and their impact on economic and social development. Three main facets will be addressed-business, public policy, and academia - with emphasis on topics related to emerging Asian markets. In addition, the Conference is aimed at sharing different historical perspectives and diverse states of knowledge, in order to enhance understanding of Asian cultures and strengthen the links between Asia, America, and Europe.

For details, contact Macau '97 Secretariat, c/o Prof. Manuel V. Heitor, Instituto Superior Técnico, Av. Rovisco Pais, 1096 Lisboa codex, Portugal; fax: 351-1-849-6156; e-mail: macao97@termcomb.ist.utl.pt 